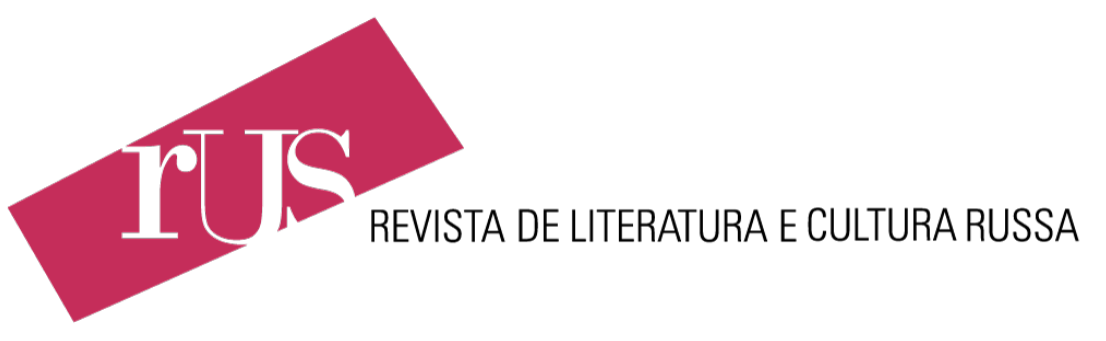

\title{
Um Catálogo de Traduções do Programa de Pós-Graduação em Literatura e Cultura Russa
}

\section{A Catalogue of the Translations from the Graduate Program in Russian Literature and Culture}

Autor: Rafael Bonavina e Raquel Siphone Edição: RUS Vol. 11. No 17

Data: Dezembro de 2020 


\section{Um Catálogo de}

Traduções do Programa

de Pós-Graduação em

Literatura e Cultura

\section{Russa}

\section{Rafael Bonavina* \\ Raquel Siphone**}

Resumo: Depois de constatarmos a falta de sistematização das traduções do PPG em Literatura e Cultura Russa, decidimos organizá-las em um arquivo facilmente acessível e que permita buscas rápidas em seu conteúdo. Por causa da crise sanitária, o presente catálogo encontra-se incompleto, no entanto, planeja-se a publicação de um complemento no futuro próximo.

\begin{abstract}
After acknowledging the lack of systematization of the academic translations published by the Graduate Program of Russian Literature and Culture, we have decided to assemble an easily accessible archive, that allows quick searches of its contents. Because of the sanitary crisis, the present catalogue is incomplete, however we plan on publishing the missing part soon.
\end{abstract}

Palavras-chave: Tradução; Catálogo; Literatura russa; Literatura soviética Keywords: Translation; Catalogue; Russian Literature; Soviet Literature 


\section{Introdução}

* Graduação em Letras pela Faculdade de Filosofia, Letras e Ciências Humanas da Universidade de São Paulo (FFLCH-USP), intercâmbio na Universidade Estatal de Moscou (MGU). https:// orcid.org/0000-0002-9669-7708; rafaelbonavina@gmail.com

\footnotetext{
** Graduação em Letras pela Faculdade de Filosofia, Letras e Ciências Humanas da Universidade de São Paulo (FFLCH-USP), estágio sanduíche (2020) na Faculdade de Filologia da Universidade Estatal de Moscou (FILFAK-MGU). https://orcid.org/0000-0003-22597517; siphoneraquel@gmail.com.
}

O presente trabalho tem por objetivo o levantamento e catalogação de textos traduzidos, até o momento, pelo corpo discente do Programa de Pós-Graduação (doravante apenas PPG) em Literatura e Cultura Russa da Universidade de São Paulo (DLO-FFLCH-USP). Como se pode depreender a partir da própria tradição e origem do PPG, uma de suas principais linhas de pesquisa é o campo da tradução de materiais russos para o português e sua divulgação.

Hoje podemos ver que os caminhos abertos por Boris Schnaiderman resultaram em uma grande quantidade de textos em edição inédita. Infelizmente, a circulação desse vasto material permanece muito restrita. Não tanto pela dificuldade de acesso - no caso do repositório virtual -, mas pelo desconhecimento do próprio conteúdo em si, posto que atualmente o PPG disponibiliza em acesso gratuito e irrestrito 92 arquivos no banco de teses da USP.

No entanto, essa falta de padronização na identificação das traduções literárias e técnicas, por vezes indicadas apenas como "Anexo" ou "Apêndice", dificulta o acesso ao texto traduzido sem o conhecimento específico da escolha do trabalho em questão.

Ao notarmos que os buscadores digitais apresentam certa dificuldade em encontrar essas traduções, incluídas em um arquivo maior, percebemos um ruído na comunicação acadêmica: as traduções só eram lidas por aqueles que sabiam de sua existência e onde encontrá-las. A partir dessa observação, depreendemos que os textos não atingiram o público-alvo, embora os tradutores tenham disponibilizado gratuitamente seus trabalhos. Em outras palavras, o material se tornou endógeno e muito dependente da memória dos acadêmicos atuantes.

Nosso propósito, ao elaborar este catálogo, é proporcionar ao pesquisador um sistema mais organizado de buscas das várias traduções presentes nos trabalhos deste PPG. Ao dispor- 
mos todas as traduções em um único arquivo, com os autores e títulos dos textos traduzidos discriminados por extenso, os buscadores digitais encontrarão as informações necessárias, facilitando $o$ acesso.

Em virtude da atual crise sanitária mundial, pudemos consultar integralmente apenas os materiais digitalizados. Pretendemos, no entanto, continuar nosso levantamento no arquivo físico da Biblioteca Florestan Fernandes assim que a situação esteja normalizada, pois há notícia de muitas traduções de acesso ainda mais difícil.

\section{Catálogo de traduções realizadas no Programa de Pós-Graduação em Literatura e Cultura Russa (DLO-FFLCH)}

Anna Akhmátova (1889-1966).

"Adolfo de Benjamin Constant na Criação de Púchkin"; "Comentário sobre O conto do Galo de Ouro e O Czar Viu Diante de Si"; "O Convidado de Pedra de Púchkin"; "O Último Conto Maravilhoso de Púchkin". In: OLIVEIRA, Deise de. Ensaios de Anna Akhmátova sobre Aleksandr Púchkin: diálogo entre escritores. 2017. Tese (Doutorado em Literatura e Cultura Russa) - Faculdade de Filosofia, Letras e Ciências Humanas, Universidade de São Paulo, São Paulo, 2017, pp. 163-169. Disponível em:

https://teses.usp.br/teses/disponiveis/8/8155/tde-04042018170614/pt-br.php.

Aleksandr Aleksandrovitch Blok (1880-1921).

"A desconhecida"; "O Rei na Praça; Sobre Amor, Poesia e o Serviço Civil"; "Teatrinho de Feira". In: HORA, Danilo Batista. Os Dramas líricos de Aleksandr Blok: tradução e comentário. 2019. Dissertação (Mestrado em Literatura e Cultura Russa) Faculdade de Filosofia, Letras e Ciências Humanas, Universidade de São Paulo, São Paulo, 2019, pp. 114-146. Disponível em: https://teses.usp. br/teses/disponiveis/8/8155/tde-30072019161036/pt-br.php. 
Aleksandr Ivánovitch Herzen (1812-1870).

"Moscou e Petersburgo"; "Trechos do Conto 'Estação Edrovo"'. In: AMÉRICO, Edélcio Rodiney. Os textos de Moscou e São Petersburgo como reflexo da identidade nacional russa. 2011. Tese (Doutorado em Literatura e Cultura Russa) - Faculdade de Filosofia, Letras e Ciências Humanas, Universidade de São Paulo, São Paulo, 2011, pp. 226-237. Disponível em:

https://teses.usp. br/teses/disponiveis/8/8155/tde-13062012154434/pt-br.php.

\section{Aleksandr Nikoláevitch Afanássiev (1826-1871).}

"A Baba-Iagá e o menino audacioso"; "A pena Finíst, o falcão brilhante"; "a tsarevna-rã"; "Conto sobre o jovem valente, as maçãs da juventude e a água da vida II"; "Conto sobre o jovem valente, as maçãs da juventude e a água da vida III"; "Ivachko e a bruxa IV"; "Ivan-tasrévitche e Biélyi Poliánin"; "O leite de animal selvagem"; "O tsar-urso"; "Os bogatyrí Medviédko, Ussýnia, Gvachko e Dubýnia"; "Vassilíssa, a bela". In: CAROLINSKI, Flavia Cristina Moino. Aleksandr Nikoláevitch Afanássiev e o conto popular russo. 2008. Dissertação (Mestrado em Literatura e Cultura Russa) - Faculdade de Filosofia, Letras e Ciências Humanas, Universidade de São Paulo, São Paulo, 2008, pp. 9395. Disponível em:

\section{https://teses.usp. br/teses/disponiveis/8/81orýnia e 55/tde- 12092008-170622/pt-br.php.}

\section{Aleksandr Serguéievitch Griboiédov (1795-1829).}

"Gorie ot Uma". In: RAMOS, Polyana de Almeida. Gorie ot uma, de Aleksandr Griboiédov tradução e aproximações. 2010. Dissertação (Mestrado em Literatura e Cultura Russa) - Faculdade de Filosofia, Letras e Ciências Humanas, Universidade de São Paulo, São Paulo, 2011, pp. 31-186. Disponível em:

https://teses.usp. br/teses/disponiveis/8/8155/tde-31052011161733/pt-br.php.

Aleksandr Serguéievitch Púchkin (1799-1837).

"Academia Russa"; "Carta ao Editor"; "Novos Livros: sobre as obrigações do homem: compêndio de Silvio Pellico"; "Novos Livros: Vastola, ou O desejo"; "O Cavaleiro Ávaro"; "Voltaire"; 
"Sobre a História de Pugatchióv". In: VITORINO, Fabrício Yuri de Souza. 'O contemporâneo': a vertente jornalística de Púchkin na primeira metade do século XIX. 2015. Dissertação (Mestrado em Literatura e Cultura Russa) - Faculdade de Filosofia, Letras e Ciências Humanas, Universidade de São Paulo, São Paulo, 2015, p. 39-44. Disponível em:

https://teses.usp. br/teses/disponiveis/8/8155/tde-19012017122020/pt-br.php.

"A Nevasca"; "A Senhorita Camponesa"; "Do Editor"; "História do Povoado de Goriúkhino". In: MENDES, Cecília Rosas. A literatura e seus variados fins domésticos: tradução e comentário de quatro contos de Púchkin. 2009. Dissertação (Mestrado em Literatura e Cultura Russa) - Faculdade de Filosofia, Letras e Ciências Humanas, Universidade de São Paulo, São Paulo, 2009, pp. 21-33. Disponível em:

https://teses.usp. br/teses/disponiveis/8/8155/tde-09122009111038/pt-br.php.

\section{Boris Leonidovitch Pasternak (1890-1960).}

"Cartas de 1922 a 1926". In: MENDES, Cecília Rosas. O fio longo dos espaços: a correspondência entre Marina Tsvetáieva e Boris Pasternak (1922-1926). 2018. Tese (Doutorado em Literatura e Cultura Russa) - Faculdade de Filosofia, Letras e Ciências Humanas, Universidade de São Paulo, São Paulo, 2018, pp. 32275. Disponível em:

https://teses.usp. br/teses/disponiveis/8/8155/tde-09042019124337/pt-br.php.

\section{Boris Mikháilovitch Eikhenbaum (1886-1959).}

"O jovem Tolstói (Primeiro capítulo)". In: ERASSO, Natalia Cristina Quintero. O diário de juventude de Liev Tolstói: singularidades do 'diário de escritor' e confluências com a prosa artística. 2016. Tese (Doutorado em Literatura e Cultura Russa) - Faculdade de Filosofia, Letras e Ciências Humanas, Universidade de São Paulo, São Paulo, 2016, pp. 137-182. Disponível em: https://teses.usp. br/teses/disponiveis/8/8155/tde-08082019120851/pt-br.php. 


\section{Daniil Kharms (1905-1942).}

"Cadernetas e Diário". In: MOUNTIAN, Daniela. Mitologia poética de Daniil Kharms. 2017. Tese (Doutorado em Literatura e Cultura Russa) - Faculdade de Filosofia, Letras e Ciências Humanas, Universidade de São Paulo, São Paulo, 2016, pp. 105328. Disponível em:

\section{https://teses.usp.br/teses/disponiveis/8/8155/tde-08032017- 142720/pt-br.php.}

"A Lebre e o Ouriço"; "A Pena da Águia Dourada"; "A Raposa e a Lebre"; "Certa Vez, o Leão, o Elefante, a Girafa, a Rena, o Avestruz, o Alce"; "Certa vez, Pétia Pregov"; "Como Kolka Pánkin Voou para o Brasil e Pietka Erchov Não Acreditou em Nada"; "Como Macha fez o Burro Levá-la para a Cidade"; "Como uma Velhinha Comprava Tinta"; "Em Cada Escola dos Estados Unidos há um Cartaz Pendurado"; "Em Primeiro e em Segundo Lugar"; "Era Verão. O Sol Brilhava. Fazia Muito Calor"; "Kolpakov, o Fanfarrão"; "No Ano Passado Fui Comemorar o Ano Novo na Casa de Meus Amigos e Amigas"; "O Fusível Travesso"; "Olha, Liénotchka, - disse a tia - vou sair"; "O Professor Trúbotchkin"; "O Ouriço Valente"; "O Quebra-ossos"; "Os Dezessete Cavalos"; "Os Dois Amigos, Kólia Kókin e Vânia Mókhin"; "Os Sete Gatos; Púchkin"; "Sobre o Cachorro Bububu"; "Um Acontecimento Misterioso"; "Um Atrás do Outro"; "Um Conto Maravilhoso"; "Uma Vez, Comprei um Lápis, Fui para Casa e Sentei para Desenhar"; "Uma Vez Perguntaram-me Como Funciona o Automóvel"; "Você esteve no Jardim Zoológico?"; "Volódia Estava na Festa de Ano Novo"; "Volódia Estava Sentado à Mesa Desenhando". In: PAIXÃO, Bianca Alves da. A literatura infantil de Daniil Kharms: tradição e modernidade. 2015. Dissertação (Mestrado em Literatura e Cultura Russa) - Faculdade de Filosofia, Letras e Ciências Humanas, Universidade de São Paulo, São Paulo, 2015, pp. 131-133. Disponível em:

https://teses.usp. br/teses/disponiveis/8/8155/tde-12012016122954/pt-br.php. 


\section{Dmítri Aleksandrovitch Prigov (1940-2007).}

"Coletânea de Poemas Cinquenta Lágrimas de Sangue num Meio Absorvente". In: CEZAR, Luiz Alberto. Cinquenta gotas de sangue: a estética conceitualista de Dmitri Prigov. 2007. Dissertação (Mestrado em Literatura e Cultura Russa) - Faculdade de Filosofia, Letras e Ciências Humanas, Universidade de São Paulo, São Paulo, 2007, pp. 67-113. Disponível em:

https://teses.usp. br/teses/disponiveis/8/8155/tde-10012008114027/pt-br.php.

\section{Dmítri Lvovich Býkov (1967-).}

"Almôndegas 'tolstoístas"'; "Assassinato no Expresso do Oriente"; "Instruções"; “O Condutor". In: PEREIRA, Eloah Pina. Contos de ferrovias de Dmítri Býkov: um estudo descritivo sobre tradução e intertexto. 2017. Dissertação (Mestrado em Literatura e Cultura Russa) - Faculdade de Filosofia, Letras e Ciências Humanas, Universidade de São Paulo, São Paulo, 2017, pp. 3950. Disponível em:

\section{https://teses.usp. br/teses/disponiveis/8/8155/tde-06062018- 123206/pt-br.php.}

\section{Evguéni Vladímirovitch Kharitónov (1941-1981).}

"A., R., eu"; "Aliocha Serioja"; "História de um garoto - 'Como me tornei assim";; "O Forno"; "Um assim, o outro assado". In: OLIVEIRA, Yuri Martins de. 'O forno', de Evguéni Kharitónov: um estudo sobre o narrador-protagonista. 2019. Dissertação (Mestrado em Literatura e Cultura Russa) - Faculdade de Filosofia, Letras e Ciências Humanas, Universidade de São Paulo, São Paulo, 2019, p. 159-164. Disponível em:

\section{https://teses.usp. br/teses/disponiveis/8/8155/tde-23072019-} 142859/pt-br.php.

\section{Fazil Abdulovich Iskander (1929-2016).}

"A Constelação de Capriuro". In: SILVA, Gabriela Soares da. A constelação de capriuro, de Fazil Iskander: tradução e comentário. 2012. Dissertação (Mestrado em Literatura e Cultura Russa) - Faculdade de Filosofia, Letras e Ciências Humanas, 
Universidade de São Paulo, São Paulo, 2012, pp. 55-173. Disponível em:

https://teses.usp. br/teses/disponiveis/8/8155/tde-05072012135750/pt-br.php.

Fiódor Mikháilovitch Dostoiévski (1821-1881).

"Uma anedota desagradável". In: RAZVICKAS, Anna Clara Versolato. O universo grotesco em Uma anedota desagradável, de Dostoiévski. 2016. Dissertação (Mestrado em Literatura e Cultura Russa) - Faculdade de Filosofia, Letras e Ciências Humanas, Universidade de São Paulo, São Paulo, 2016, pp. 12-63 Disponível em:

https://teses.usp. br/teses/disponiveis/8/8155/tde-09122016135436/pt-br.php.

Isaac Emmanuilovitch Babel (1894-1940).

"Diário de 'O Exército de Cavalaria' de 1920". In: MALARENKO, Henady. Isaak Bábel e o seu Diário de Guerra de 1920. 2011. Tese (Doutorado em Literatura e Cultura Russa) - Faculdade de Filosofia, Letras e Ciências Humanas, Universidade de São Paulo, São Paulo, 2011, pp. 113-267. Disponível em:

https://teses.usp. br/teses/disponiveis/8/8155/tde-11102011133125/pt-br.php.

\section{Iúri Karlovitch Oliécha (1899-1960).}

"Discurso para o I Congresso da União dos Escritores Soviéticos". In: MARTINS, Phillipe de Souza. Arquétipos literários no romance Inveja, de Iuri Oliecha. 2019. Dissertação (Mestrado em Literatura e Cultura Russa) - Faculdade de Filosofia, Letras e Ciências Humanas, Universidade de São Paulo, São Paulo, 2019, pp. 101-105. Disponível em:

https://www.teses.usp. br/teses/disponiveis/8/8155/tde02122019-154856/pt-br.php.

Iúri Mikháilovitch Lotman (1922-1993).

"Entre a Liberdade e a Vólia". "O destino de Fiédia Protássov". In: BYTSENKO, Anastassia. Liev Tolstói e o teatro: texto e contexto de O Cadáver Vivo. 2013. Tese (Doutorado em Literatura 
e Cultura Russa) - Faculdade de Filosofia, Letras e Ciências Humanas, Universidade de São Paulo, São Paulo, 2013, pp. 178186. Disponível em:

https://teses.usp. br/teses/disponiveis/8/8155/tde-13022014114418/pt-br.php.

"A cultura como intelecto coletivo e os problemas da inteligência artificial"; "A semiótica da cultura e o conceito de texto"; "A saída do labirinto. No limiar do imprevisível. A última entrevista do imprevisível"; "O fenômeno da arte"; "O fenômeno da cultura"; "O problema da tradução poética"; "O problema do texto"; "Propostas em relação ao programa da IV Escola de verão sobre os sistemas secundários de modelação"; "Sobre a dinâmica da cultura". In: AMÉRICO, Ekaterina Volkova. Alguns aspectos da semiótica da cultura de Iúri Lótman. 2012. Tese (Doutorado em Literatura e Cultura Russa) - Faculdade de Filosofia, Letras e Ciências Humanas, Universidade de São Paulo, São Paulo, 2012, pp. 255-279. Disponível em:

https://teses.usp. br/teses/disponiveis/8/8155/tde-07112012124602/pt-br.php.

\section{Ivan Rébrin.}

"Sobre emigração para o Brasil". In: BYTSENKO, Anastassia. Imigração da Rússia para o Brasil no início do século XX. Visões do paraíso e do inferno. 2006. Dissertação (Mestrado em Literatura e Cultura Russa) - Faculdade de Filosofia, Letras e Ciências Humanas, Universidade de São Paulo, São Paulo, 2006, pp. 106-118. Disponível em:

https://teses.usp. br/teses/disponiveis/8/8155/tde-12112007132926/pt-br.php.

\section{Ivan Serguéievitch Turguênev (1818-1883).}

"Andrei Kólossov". In: ESTEVES, Renata. Turguêniev e a inovação literária. 2018. Tese (Doutorado em Literatura e Cultura Russa) - Faculdade de Filosofia, Letras e Ciências Humanas, Universidade de São Paulo, São Paulo, 2018, pp. 63-89. Disponível em:

https://teses.usp. br/teses/disponiveis/8/8155/tde-10122018132420/pt-br.php. 
"Klara Mílitch". In: MOURA, Giselle B Mussi de. 'Klara Mílitch' (depois da morte) de Ivan S. Turguêniev: estudo e tradução. 2015. Dissertação (Mestrado em Literatura e Cultura Russa) Faculdade de Filosofia, Letras e Ciências Humanas, Universidade de São Paulo, São Paulo, 2015, pp. 82-140. Disponível em:

https://teses.usp.br/teses/disponiveis/8/8155/tde-22122015112122/pt-br.php?fbclid=IwAR16kXdQhi0d_SC9zXNJAcklW4cjEmyKtren2tSSwuz_axhX5QIV42VbIIM

"O rei Lear da estepe". In: FARJADO, Jéssica de Souza. O rei Lear da estepe, de Ivan Turguêniev: uma tragédia russa. 2016. Dissertação (Mestrado em Literatura e Cultura Russa) - Faculdade de Filosofia, Letras e Ciências Humanas, Universidade de São Paulo, São Paulo, 2016, pp. 9-90. Disponível em:

https://teses.usp. br/teses/disponiveis/8/8155/tde-03052016110236/pt-br.php.

\section{Janis Gutmann.}

"Vida dos colonos do estado de São Paulo do Brasil". In: BYTSENKO, Anastassia. Imigração da Rússia para o Brasil no início do século XX. Visões do paraíso e do inferno. 2006. Dissertação (Mestrado em Literatura e Cultura Russa) - Faculdade de Filosofia, Letras e Ciências Humanas, Universidade de São Paulo, São Paulo, 2006, pp. 69-72. Disponível em:

https://teses.usp. br/teses/disponiveis/8/8155/tde-12112007132926/pt-br.php.

\section{Konstantin Serguéievitch Alekseev (Stanislavski) (1863-} 1938).

"Aula 30/05/1935"; "Aula de 4/06/1935"; "Aula de 5/11/1935"; "Aula de 9/11/1935"; "Aula de 11/11/1935"; "Aula de 15/11/1935"; "Aula de 17/11/1935"; "Aula de 19/11/1935"; "Aula de 25/11/1935"; "Aula de 5/12/1935"; "Aula de 7/12/1935"; "Aula de 13/12/1935"; "Aula de 27/04/1935"; "Aula de 25/05/1935"; "Conversa com os Alunos do GITIS em 15/05/1938"; "Conversa Final com o Grupo de Pedagogos-assistentes em 22/05/1938"; "Plano Pedagógico do Estúdio". In: MOSCHKOVICH, Diego Fernandes Garcia. O último Stanislávski em ação: tradução e análise das experiências do Estúdio de Ópera e Arte Dramática (1935 - 1938). 2019. 
Dissertação (Mestrado em Literatura e Cultura Russa) - Faculdade de Filosofia, Letras e Ciências Humanas, Universidade de São Paulo, São Paulo, 2019. Disponível em:

\section{https://teses.usp. br/teses/disponiveis/8/8155/tde-25102019- 184745/pt-br.php.}

"Partituras para 'As três irmãs', de Tchekhov". In: BARBOSA, Tieza Tissi. As partituras de Stanislávski para As três irmãs, de Tchekhov: tradução e análise da composição espacial da encenação. 2012. Dissertação (Mestrado em Literatura e Cultura Russa) - Faculdade de Filosofia, Letras e Ciências Humanas, Universidade de São Paulo, São Paulo, 2012, pp. 21-598. Disponível em:

https://teses.usp. br/teses/disponiveis/8/8155/tde-28022013115838/pt-br.php.

\section{Leopold Antônovich Sulerjítski (1872-1916).}

"Dos Diários (1913-1914)"; "Sobre as Relações Entre Ator e Diretor". In: MERINO, Daniela Simone Terehoff. Mestre de teatro, mestre da vida: Leopold Sulerjítski e sua busca artística e pedagógica. 2017. Dissertação (Mestrado em Literatura e Cultura Russa) - Faculdade de Filosofia, Letras e Ciências Humanas, Universidade de São Paulo, São Paulo, 2016, pp. 155-162. Disponível em:

https://teses.usp. br/teses/disponiveis/8/8155/tde-09032017091918/pt-br.php.

\section{Lev Nikoláevitch Tolstói (1828-1910).}

"Aliocha, o Pote"; "Terceiro Livro de Leitura"; "Correspondência entre Lev N. Tolstói e Mohandas K. Ghandi". In: RABELLO, Belkis. As cartilhas e os livros de leitura de Lev N. Tolstói. 2009. Dissertação (Mestrado em Literatura e Cultura Russa) - Faculdade de Filosofia, Letras e Ciências Humanas, Universidade de São Paulo, São Paulo, 2009, pp. 261-267. Disponível em:

https://teses.usp.br/teses/disponiveis/8/8155/tde-19022010163110/pt-br.php.

"Diários (1847-1854)". In: ERASSO, Natalia Cristina Quintero. Os diários de juventude de Liev Tolstói, tradução e questões sobre o gênero de diário. 2011. Dissertação (Mestrado em Literatura e 
Cultura Russa) - Faculdade de Filosofia, Letras e Ciências Humanas, Universidade de São Paulo, São Paulo, 2011, pp. 29-146. Disponível em:

https://teses.usp.br/teses/disponiveis/8/8155/tde-14072011111923/pt-br.php.

\section{Lev Semiónovitch Vygotsky (1896-1934).}

"A arte gráfica de Bykhovski"; "Abertura da temporada"; "[Acerca do encerramento da temporada] Sobre o autor de 'não exatamente uma resenha"; "Balé de Kharkiv"; "Crime e castigo Outono dourado - Ralé"; "[De segunda a segunda] Turnês de Utiôsov e Foregger"; "Fraque bem costurado"; "[Não exatamente uma resenha] Intriga e amor - falcões e corvos"; "No intervalo entre as turnês"; "Notas sobre o teatro judaico"; "O filhote da águia - O discípulo do diabo"; "O inspetor geral - Flávia Tessini - O preço da vida - O cantor do próprio sofrimento - O moscardo"; "O Rei está Nu"; "O tolo - A grosseirona"; "Pantera negra - Almas de lobo"; "Primeira andorinha. O dibuk na montagem de Rubin"; "Sobre o teatro infantil"; "Teatro e Revolução"; "Teatro Judaico. A feiticeira - Dos ferblonzele cheifele"; "Teatro Judaico. Bar Kohba - Der Yeshiva Bokher"; "Teatro Judaico. Homenagem a S. I. Eidelman"; "Teatro Judaico. Silva. A mensh zol men zein"; "Turnê da Companhia Solovtsóv"; "Turnê de opereta"; "Turnês de Utiôsov e Foregger"; "Turnê E. V. Guéltser"; "Uriel Acosta - A tempestade". In: MARQUES, Priscila Nascimento. O Vygótski incógnito: escritos sobre arte (1915-1926). 2015. Tese (Doutorado em Literatura e Cultura Russa) - Faculdade de Filosofia, Letras e Ciências Humanas, Universidade de São Paulo, São Paulo, 2015, pp. 230-233. Disponível em:

https://teses.usp. br/teses/disponiveis/8/8155/tde-06102015161300/pt-br.php.

\section{Lídia Iakovlevna Guinzburg (1902-1990).}

"Introdução à obra Sobre a Prosa Psicológica". In:ERASSO, Natalia Cristina Quintero. O diário de juventude de Liev Tolstói: singularidades do 'diário de escritor' e confluências com a prosa artística. 2016. Tese (Doutorado em Literatura e Cultura Russa) - Faculdade de Filosofia, Letras e Ciências Humanas, Universidade de São Paulo, São Paulo, 2016, pp. 94-136. Disponível em: 
https://teses.usp. br/teses/disponiveis/8/8155/tde-08082019120851/pt-br.php.

\section{Lídia Kornéievna Tchukóvskaia (1907-1996).}

"Sofia Petróvna". In: CAMARGO-SIPIONATO, Maria. Sófia Petrovna e a memória proibida do cotidiano soviético. 2014. Dissertação (Mestrado em Literatura e Cultura Russa) - Faculdade de Filosofia, Letras e Ciências Humanas, Universidade de São Paulo, São Paulo, 2014, pp. 48-143. Disponível em:

https://teses.usp. br/teses/disponiveis/8/8155/tde-06112014191212/pt-br.php.

\section{Marina Ivánovna Tsvetáieva (1892-1941).}

"Para Akhmátova". In: NOGUEIRA, André Bacciotti. Uma 'Mãe de Deus flagelante': santidade e heresia em Para Akhmátova de Marina Tsvetáieva. 2018. Dissertação (Mestrado em Literatura e Cultura Russa) - Faculdade de Filosofia, Letras e Ciências Humanas, Universidade de São Paulo, São Paulo, 2018. Disponível em:

https://teses.usp. br/teses/disponiveis/8/8155/tde-29082018142032/pt-br.php.

"O meu Púchkin". In: ALMEIDA, Paula Costa Vaz de. O meu Púchkin de Marina Tsvetáieva: tradução e apresentação. 2008. Dissertação (Mestrado em Literatura e Cultura Russa) - Faculdade de Filosofia, Letras e Ciências Humanas, Universidade de São Paulo, São Paulo, 2008, pp. 43-121. Disponível em:

https://teses.usp. br/teses/disponiveis/8/8155/tde-19102009144635/pt-br.php.

"Uma aventura. Peça em cinco atos". In: CAREGARO, Raquel Arantes Toledo. Uma aventura: o teatro de Marina Tsvetáieva. Tradução e apresentação. 2015. Dissertação (Mestrado em Literatura e Cultura Russa) - Faculdade de Filosofia, Letras e Ciências Humanas, Universidade de São Paulo, São Paulo, 2015, pp. 62-123. Disponível em:

https://teses.usp. br/teses/disponiveis/8/8155/tde-02102015111508/pt-br.php. 
"Cartas de 1922 a 1926". In: MENDES, Cecília Rosas. O fio longo dos espaços: a correspondência entre Marina Tsvetáieva e Boris Pasternak (1922-1926). 2018. Tese (Doutorado em Literatura e Cultura Russa) - Faculdade de Filosofia, Letras e Ciências Humanas, Universidade de São Paulo, São Paulo, 2018, pp. 32275. Disponível em:

https://teses.usp. br/teses/disponiveis/8/8155/tde-09042019124337/pt-br.php.

\section{Mikhail Ievgrafovitch Saltykov-Schedrin (1826-1889).}

"História de uma cidade". In: SALES, Denise Regina de. A sátira de Saltykóv-Schedrin em História de uma Cidade. 2010. Tese (Doutorado em Literatura e Cultura Russa) - Faculdade de Filosofia, Letras e Ciências Humanas, Universidade de São Paulo, São Paulo, 2011, pp. 16-217. Disponível em:

https://teses.usp. br/teses/disponiveis/8/8155/tde-15092011134400/pt-br.php. Acesso em: 2020-07-06.

\section{Mikhail Iúrievitch Lérmontov (1814-1841).}

"Panorama de Moscou". In: AMÉRICO, Edélcio Rodiney. Os textos de Moscou e São Petersburgo como reflexo da identidade nacional russa. 2011. Tese (Doutorado em Literatura e Cultura Russa) - Faculdade de Filosofia, Letras e Ciências Humanas, Universidade de São Paulo, São Paulo, 2011, pp. 209-214. Disponível em:

https://teses.usp. br/teses/disponiveis/8/8155/tde-13062012154434/pt-br.php.

\section{Mikhail Mikháilovitch Scherbátov (1733-1790).}

"Petição de Moscou referente ao seu esquecimento". In: AMÉRICO, Edélcio Rodiney. Os textos de Moscou e São Petersburgo como reflexo da identidade nacional russa. 2011. Tese (Doutorado em Literatura e Cultura Russa) - Faculdade de Filosofia, Letras e Ciências Humanas, Universidade de São Paulo, São Paulo, 2011, pp. 199-208. Disponível em: https://teses.usp. br/teses/disponiveis/8/8155/tde-13062012154434/pt-br.php. 
Mikhail Nikoláievitch Zagóskin (1789-1852).

"Dois caracteres: Irmão e Irmã". In: AMÉRICO, Edélcio Rodiney. Os textos de Moscou e São Petersburgo como reflexo da identidade nacional russa. 2011. Tese (Doutorado em Literatura e Cultura Russa) - Faculdade de Filosofia, Letras e Ciências Humanas, Universidade de São Paulo, São Paulo, 2011, pp. 219225. Disponível em:

https://teses.usp. br/teses/disponiveis/8/8155/tde-13062012154434/pt-br.php.

\section{Mikhail Vassílevitch Lomonóssov (1711-1765). “}

Carta sobre as regras de versificação russa"; "Ode à abençoada memória da soberana imperatriz Ana Ioânovna pela vitória sobre os turcos e tártaros e a tomada da fortaleza da Khotin no ano de 1739"; "Ode ao dia de ascensão ao trono de Todas as Rússias de sua Majestade Soberana, a Imperatriz Elizabete Petrovna, no ano de 1747"; "Prólogo a Respeito da Utilidade de Livros Eclesiásticos em Língua Russa”. In: FRATE, Rafael Nogueira de Carvalho. Mikhail Vassílievitch Lomonóssov: uma apresentação. 2016. Dissertação (Mestrado em Literatura e Cultura Russa) - Faculdade de Filosofia, Letras e Ciências Humanas, Universidade de São Paulo, São Paulo, 2016, pp. 204209. Disponível em:

https://teses.usp. br/teses/disponiveis/8/8155/tde-09122016144520/pt-br.php.

Nestor, o Cronista (1056-114).

"Narrativa dos Anos Passados". In: SIMONE, Lucas Ricardo. Recontar o tempo: apresentação e tradução de Narrativa dos anos passados. 2019. Tese (Doutorado em Literatura e Cultura Russa) - Faculdade de Filosofia, Letras e Ciências Humanas, Universidade de São Paulo, São Paulo, 2019, pp. 65-282. Disponível em:

https://teses.usp. br/teses/disponiveis/8/8155/tde-21082019115908/pt-br.php.

Nikolai Vasílevitch Gógol (1809-1852).

"A Noite na véspera do dia de Ivan Kupala"; "Uma noite de maio, ou a moça afogada". In: PETROVA, Maria. A poética do romance gótico na coletânea Noites em uma granja perto de 
Dikanka de N.V. Gógol. 2016. Dissertação (Mestrado em Literatura e Cultura Russa) - Faculdade de Filosofia, Letras e Ciências Humanas, Universidade de São Paulo, São Paulo, 2016, pp. 183-196. Disponível em:

https://teses.usp. br/teses/disponiveis/8/8155/tde-26082016131932/pt-br.php.

"Notas petersburguesas de 1836 (Excerto)". In: AMÉRICO, Edélcio Rodiney. Os textos de Moscou e São Petersburgo como reflexo da identidade nacional russa. 2011. Tese (Doutorado em Literatura e Cultura Russa) - Faculdade de Filosofia, Letras e Ciências Humanas, Universidade de São Paulo, São Paulo, 2011, pp. 215-218. Disponível em:

https://teses.usp. br/teses/disponiveis/8/8155/tde-13062012154434/pt-br.php.

\section{Serguêi Donavitch Dovlátov (1941-1990).}

"Parque Cultural". In: MIKAELYAN, Yulia. Serguei Dovlátov: texto de cultura na literatura russa contemporânea. 2016. Tese (Doutorado em Literatura e Cultura Russa) - Faculdade de Filosofia, Letras e Ciências Humanas, Universidade de São Paulo, São Paulo, 2016, pp. 177-269. Disponível em:

https://teses.usp. br/teses/disponiveis/8/8155/tde-14122016110500/pt-br.php.

Acesso em: 2020-07-06.

Serguêi Mikháilovitch Eisenstein (1898-1948).

"Patriotismo, meu tema". In: PEREIRA, Erivoneide Marlene de Barros. A cinematografia de Serguei Eisenstein: imagem, som e sentido em Aleksandr Niévski. 2014. Dissertação (Mestra do em Literatura e Cultura Russa) - Faculdade de Filosofia, Letras e Ciências Humanas, Universidade de São Paulo, São Paulo, 2014, pp. 127-131. Disponível em:

https://teses.usp. br/teses/disponiveis/8/8155/tde-20022015151453/pt-br.php.

Valentin Grigorievitch Raspútin (1937-2015).

"Dinheiro para Maria". In: SANTOS, Henrique Gomes Lucas. Dinheiro para Maria, de Valetin Raspútin: tradução e análise. 
2018. Dissertação (Mestrado em Literatura e Cultura Russa) Faculdade de Filosofia, Letras e Ciências Humanas, Universidade de São Paulo, São Paulo, 2018, pp. 12-105. Disponível em:

https://teses.usp. br/teses/disponiveis/8/8155/tde-30102018115858/pt-br.php.

\section{Varlam Tikhonovitch Chalámov (1907-1982)}

"Sobre a Prosa"; "Sobre a minha Prosa". In: SILVA, Andréa Zeppini Menezes da. O Plutão que veio do inferno: sobre a prosa de Varlam Chalámov. 2017. Tese (Doutorado em Literatura e Cultura Russa) - Faculdade de Filosofia, Letras e Ciências Humanas, Universidade de São Paulo, São Paulo, 2017, pp. 332350. Disponível em:

https://teses.usp.br/teses/disponiveis/8/8155/tde-16072018145148/pt-br.php.

\section{Vaska Morózov.}

"Recordações de um aluno da escola de Iásnaia Poliana"; "Vida de um Soldado". In: RABELLO, Belkis. As cartilhas e os livros de leitura de Lev N. Tolstói. 2009. Dissertação (Mestrado em Literatura e Cultura Russa) - Faculdade de Filosofia, Letras e Ciências Humanas, Universidade de São Paulo, São Paulo, 2009, pp. 198-205. Disponível em:

https://teses.usp. br/teses/disponiveis/8/8155/tde-19022010163110/pt-br.php.

\section{Velímir Khlébnikov (1885-1922).}

"Zanguézi". In: FRANCISCO JUNIOR, Mario Ramos. Zanguési, de Velimír Khlébnikov: a utopia da obra de arte como síntese perfeita do universo. 2008. Tese (Doutorado em Literatura e Cultura Russa) - Faculdade de Filosofia, Letras e Ciências Humanas, Universidade de São Paulo, São Paulo, 2008, pp. 74-127. Disponível em:

https://teses.usp. br/teses/disponiveis/8/8155/tde-30112009115402/pt-br.php.

\section{Venedikt Vassílevitch Eroféiev (1938-1990).}

"Moskvá-Petuchki". In: SOMA, Eduardo. Ulisses em tempos de estagnação: tradução e estudo de Moskvá - Petuchki, de Venedíkt Eroféiev. 2016. Dissertação (Mestrado em Literatura e 
Cultura Russa) - Faculdade de Filosofia, Letras e Ciências Humanas, Universidade de São Paulo, São Paulo, 2016, pp. 63-181. Disponível em:

https://teses.usp. br/teses/disponiveis/8/8155/tde-09122016135054/pt-br.php.

Vissarión Grigórievitch Belínski (1811-1848).

"Petersburgo e Moscou". In: AMÉRICO, Edélcio Rodiney. Os textos de Moscou e São Petersburgo como reflexo da identidade nacional russa. 2011. Tese (Doutorado em Literatura e Cultura Russa) - Faculdade de Filosofia, Letras e Ciências Humanas, Universidade de São Paulo, São Paulo, 2011, pp. 244-287. Disponível em:

https://teses.usp. br/teses/disponiveis/8/8155/tde-13062012154434/pt-br.php.

"Uma visão da literatura no ano de 1847". In: ESTEVES, Renata. Turguêniev e a inovação literária. 2018. Tese (Doutorado em Literatura e Cultura Russa) - Faculdade de Filosofia, Letras e Ciências Humanas, Universidade de São Paulo, São Paulo, 2018, pp. 90-176. Disponível em:

https://teses.usp. br/teses/disponiveis/8/8155/tde-10122018132420/pt-br.php.

\section{Vladímir Galaktionovitch Korolénko (1853-1921).}

"Iáchka"; "Sokolínets. Das narrativas sobre vagabundos". In: HAN, Catren da Silva. Vladímir G. Korolienko: contos siberianos. 2016. Dissertação (Mestrado em Literatura e Cultura Russa) - Faculdade de Filosofia, Letras e Ciências Humanas, Universidade de São Paulo, São Paulo, 2016, pp. 108-153. Disponível em: https://teses.usp. br/teses/disponiveis/8/8155/tde-02122016134430/pt-br.php.

\section{Vladímir Gueórguievitch Sorókin (1955-).}

"O jubileu". In: MARCANÇOLI, Cássia Regina Marconi. O Jubileu de Vladímir Sorókin: 'um tal Tchékhov, que nunca havíamos visto antes!'. 2017. Dissertação (Mestrado em Literatura e Cultura Russa) - Faculdade de Filosofia, Letras e Ciências 
Humanas, Universidade de São Paulo, São Paulo, 2017, pp. 4581. Disponível em:

https://teses.usp. br/teses/disponiveis/8/8155/tde-14082017111742/pt-br.php.

Vladímir Ivânovitch Niemiróvitch-Dântchenko (1858-1943). "Obras de Tolstói no Teatro de Arte". In: BYTSENKO, Anastassia. Liev Tolstói e o teatro: texto e contexto de $O$ Cadáver Vivo. 2013. Tese (Doutorado em Literatura e Cultura Russa) - Faculdade de Filosofia, Letras e Ciências Humanas, Universidade de São Paulo, São Paulo, 2013, pp. 187-205. Disponível em:

https://teses.usp. br/teses/disponiveis/8/8155/tde-13022014114418/pt-br.php.

Vladímir Vladímirovitch Maiakóvski (1893-1930).

"Flauta Vertebral"; "O Homem"; "Nuvem de Calças"; "Sobre Isto". In: MEI, Letícia Pedreira. Sobre isto: síntese da poética de Maiakóvski. 2015. Dissertação (Mestrado em Literatura e Cultura Russa) - Faculdade de Filosofia, Letras e Ciências Humanas, Universidade de São Paulo, São Paulo, 2015, pp. 24-85. Disponível em:

https://teses.usp. br/teses/disponiveis/8/8155/tde-29092015164134/pt-br.php.

\section{Vladímir Vladimirovitch Nabókov (1899-1977).}

"Cortina de Fumaça”; "Lábios Colados"; "Nuvem, lago, torre"; "O Círculo"; "O Melro"; "Outras Margens"; "Primavera em Fialta"; "Última Thule". In: URSO, Graziela Schneider. A face russa de Nabokóv: poética e tradução. 2010. Dissertação (Mestrado em Literatura e Cultura Russa) - Faculdade de Filosofia, Letras e Ciências Humanas, Universidade de São Paulo, São Paulo, 2010, pp. 75-81. Disponível em:

https://teses.usp. br/teses/disponiveis/8/8155/tde-16082016152515/pt-br.php.

Recebido em: $30 / 08 / 2020$

Aceito em: 25/11/2020

Publicado em dezembro de 2020 